\title{
CD146 mediates the anti-apoptotic role of Netrin-1 in endothelial progenitor cells under hypoxic conditions
}

\author{
RU-CHAO JIANG ${ }^{1,2^{*}}$, XUE-YING ZHENG ${ }^{1,2^{*}}$, SHENG-LAN YANG $^{1,2}$, HAI-JIE SHI ${ }^{1,2}$, \\ JIA-HUI XI ${ }^{1,2}$, YONG-JIAN ZOU ${ }^{1,2}$, HUA-QIAN DOU ${ }^{1,2}$, YUN-JING WANG ${ }^{1,2}$, \\ YUAN QIN $^{1,2}$, XIAO-LING ZHANG ${ }^{3}$ and QING XIAO ${ }^{1,2,4}$
}

\begin{abstract}
${ }^{1}$ Key Laboratory of Molecular Target and Clinical Pharmacology, School of Pharmaceutical Sciences and The Fifth Affiliated Hospital, ${ }^{2}$ Department of Pharmacology, Guangzhou Medical University, Guangzhou, Guangdong 511436; ${ }^{3}$ Department of Neonatology, Maternal and Children Hospital of Guangdong Province, Guangzhou, Guangdong 510260; ${ }^{4}$ The State Key Laboratory of Respiratory Disease and NMPA Key Laboratory for Clinical Research and Evaluation of Drug for Thoracic Diseases, Guangzhou Medical University, Guangzhou, Guangdong 511436, P.R. China
\end{abstract}

Received June 12, 2021; Accepted September 21, 2021

DOI: $10.3892 / \mathrm{mmr} .2021 .12521$

\begin{abstract}
Modulating the biological status of endothelial progenitor cells (EPCs), such as function and survival, is essential for therapeutic angiogenesis in ischemic vascular disease environments. This study aimed to explore the role and molecular mechanisms underlying Netrin-1 in the viability and angiogenic function of EPCs. EPCs were isolated from the bone barrow of adult C57/BL6 mice. The apoptosis and various functions of EPCs were analyzed in vitro by manipulating the expression of Netrin-1. The TUNEL assay was performed to detect apoptotic EPCs. Cell migration and tube formation assays were performed to detect EPC function. Trypan blue staining was performed to detect cell viability. Western blot analysis was performed to detect the protein expression levels of Netrin-1, CD146 and apoptotic factors. Quantitative PCR analysis was performed to detect the expression levels of Netrin-1 receptors. The results demonstrated that treatment with exogenous Netrin-1 promoted EPC migration and tube formation, whereas transfection with small interfering (si)RNA targeting Netrin-1 exhibited the opposite effects.
\end{abstract}

Correspondence to: Professor Qing Xiao, Department of Pharmacology, Guangzhou Medical University, 1 Guangyi South Road, Panyu, Guangzhou, Guangdong 511436, P.R. China

E-mail: xiaoqingxiaomeng@163.com

Professor Xiao-Ling Zhang, Department of Neonatology, Maternal and Children Hospital of Guangdong Province, 13 Guangyuan West Road, Guangzhou, Guangdong 510260, P.R. China

E-mail: augha@163.com

${ }^{*}$ Contributed equally

Key words: ischemic diseases, endothelial progenitor cells, hypoxia, Netrin-1, CD146
Exogenous Netrin-1 protected EPCs from hypoxia-induced apoptosis, whereas the interruption of endogenous Netrin-1 enhancement under hypoxia by Netrin-1-siRNA exacerbated the apoptosis of EPCs. Furthermore, CD146, one of the immunoglobulin receptors activated by Netrin-1, was screened for in the present study. Results demonstrated that CD146 did not participate in Netrin-1-promoted EPC function, but mediated the anti-apoptotic effects of Netrin-1 in EPCs. In conclusion, Netrin-1 enhanced the angiogenic function of EPCs and alleviated hypoxia-induced apoptosis, which was mediated by CD146. This biological function of Netrin-1 may provide a potential therapeutic option to promote EPCs for the treatment of ischemic vascular diseases.

\section{Introduction}

Endothelial progenitor cells (EPCs) are used as an important source of autologous cell therapy for the treatment of ischemic diseases $(1,2)$. EPCs, which are derived from hematopoietic stem cells, have significant angiogenic functions and are mainly located in the bone marrow. EPCs are also found in the fetal liver, umbilical cord blood and skeletal muscle (3). When stimulated by various physiological or pathological factors, such as vascular development, diabetes, myocardial infarction and hypertension, EPCs are mobilized from the bone marrow to the peripheral blood, participating in the repair and angiogenesis of damaged blood vessels (4). In animal models of experimental ischemic injuries, the transplantation of EPCs exhibits an ischemic neovascularization capacity, thereby improving the perfusion and function of ischemic tissue $(5,6)$. In pilot clinical trials, treating patients with severe limb ischemia and acute myocardial infarction with EPCs was beneficial for neovascularization and blood supply (7). However, numerous studies have indicated that most of the transplanted EPCs are unable to survive when they are injected into the ischemic site due to the harsh conditions of the living environment, including ischemia, hypoxia and 
nutrient deficiencies (8-10). These issues limit the clinical development of EPCs in the treatment of ischemic diseases. Therefore, the mechanism underlying EPC damage in an ischemic microenvironment should be explored to find suitable targets and improve the function and survival of EPCs.

Netrin-1 is a multifunctional secreted protein that belongs to the Netrin family and is best known for guiding the movement of neurons in the development of the central nervous system (11). Netrin-1 contributes to the nervous system via axonal guidance, Schwann cell proliferation and migration, nerve regeneration and functional recovery, and participates in the pathology of several diseases, such as the myocardial ischemia, cerebral ischemia, acute kidney injury, blood vessels, liver, acute and chronic kidney injury, pathogenic bone degradation and diabetic retinopathy (12). The role of Netrin-1 in vessel formation is mostly associated with endothelial cells (13). EPCs are the progenitors of endothelial cells, and the results of a previous study indicated that Netrin-1 attenuates neointimal formation partly by enhancing EPC homing and proliferation, and by producing nitrous oxide (14). However, the effects of Netrin-1 on the pro-angiogenic function of EPC and survival under hypoxic conditions are yet to be fully elucidated. The present study aimed to investigate the status of EPCs in hypoxic condition.

\section{Materials and methods}

Animals. A total of 35 C57/BL6 adult (8 weeks, $22 \mathrm{~g}$ ) mice purchased from the Animal Center of Southern Medical University were used in the present study. All animal procedures were in accordance with the National Institutes of Health guidelines (15). All animal procedures were performed complying with the Institutional Animal Ethics Committee of Guangzhou Medical University (Guangzhou, China), and approved by the Institutional Animal Ethics Committee of Guangzhou Medical University (approval no. GY2018-092). Mice were maintained at $21-23^{\circ} \mathrm{C}$, with a humidity of 40-55\% and a 12-h light cycle (lights on 06:00-18:00), with free access to food and water.

Isolation, culture and treatment of mouse-derived bonemarrow EPCS. The following procedures were carried out according to previously used methods (16-18). Briefly, adult male C57/BL6 mice were sacrificed by intraperitoneal injection with an overdose of sodium pentobarbital $(100 \mathrm{mg} / \mathrm{kg})$, followed by cervical dislocation. Mononuclear cells were isolated from the bone marrow of the tibias and femurs of mice. Bone marrow was flushed out of the tibias and femurs with Endothelial Cell Growth Basal Medium-2 (EBM-2; Lonza Group, Ltd.) using a 25-gauge needle, separated with vigorous pipetting and subsequently centrifuged for $5 \mathrm{~min}$ at $400 \mathrm{x} \mathrm{g}$ at $4^{\circ} \mathrm{C}$. Red blood cells were lysed using ammonium chloride solution (Beyotime Institute of Biotechnology) and washed three times in Endothelial Cell Growth Medium-2 (EGM-2, Lonza Group, Ltd.), and subsequently centrifuged for $5 \mathrm{~min}$ at $400 \mathrm{x} \mathrm{g}$ at $4^{\circ} \mathrm{C}$. Cells were cultured at $37^{\circ} \mathrm{C}$ in fibronectin (Corning, Inc.)-coated 6-well plates in EGM-2 [EBM-2, vascular endothelial growth factor (VEGF), hydrocortisone, human fibroblastic growth factor, IGF, ascorbic acid, human epidermal growth factor, heparin and 5\% FBS; Lonza Group, Ltd.]. After
3 days, non-adherent cells were removed by rinsing with PBS. Subsequently, EGM-2 was changed daily. The 7-day EPCs were subjected to the following treatment options: a) 100 or $200 \mathrm{ng} / \mathrm{ml}$ Netrin-1 (delivered according to the concentration of Netrin-1 in endothelial cells from previous studies (19-22): i) Control; ii) Netrin-1 $(100 \mathrm{ng} / \mathrm{ml})$ and iii) Netrin-1 (200 ng/ml); b) oxygen and glucose deprivation (OGD) stimulation (applied according to our previous studies): i) Control; ii) OGD 2 h; iii)OGD 4 h; iv) OGD 6 h; v) OGD 12 h $(1,14)$; or c) Netrin-1-small interfering (si)RNA or CD146-siRNA: i) Control; ii) Netrin-1-siRNA-1; iii) Netrin-1-siRNA-2; iv) Netrin-1-siRNA-3; v) CD146-siRNA-1; vi) CD146-siRNA-2 and vii) CD146-siRNA-3.

Transwell migration assay. Transwell assays (Corning, Inc.) were used to evaluate the migration of EPCs. EPCs were divided into four groups: i) Control; ii) Netrin-1 (200 ng/ml); iii) Netrin-1-siRNA; and iv) Netrin-1 $(200 \mathrm{ng} / \mathrm{ml})+$ CD146-siRNA. A total of $5 \times 10^{4}$ cells/well were seeded into the upper chambers in EBM-2 (Lonza Group, Ltd.), while human VEGF (R\&D Systems, Inc.) and EBM-2 were added into the lower chambers. After $24 \mathrm{~h}$ of culture at $37^{\circ} \mathrm{C}$, cells were fixed in $4 \%$ paraformaldehyde for $20 \mathrm{~min}$ and stained with crystal violet for $30 \mathrm{~min}$ at $37^{\circ} \mathrm{C}$. The number of migrated cells was observed and recorded under an inverted light microscope (Nikon Corporation), quantified and averaged by examining five random microscopic fields (magnification, $\mathrm{x} 100$ ).

Tube formation assay. EPCs were divided into four groups: i) Control; ii) Netrin-1 (200 ng/ml); iii) Netrin-1-siRNA; and iv) Netrin-1 (200 ng/ml) + CD146-siRNA. EPCs were seeded in 48 -well culture plates $\left(5 \times 10^{4}\right.$ cells/well) coated with Matrigel (Corning, Inc.), which was precoated for $1 \mathrm{~h}$ at $37^{\circ} \mathrm{C}$, and EGM-2 was added. After incubation at $37^{\circ} \mathrm{C}$ for $24 \mathrm{~h}$, tube formation was counted in 4 random fields at $\mathrm{x} 40$ magnification, with a Nikon 2000 anatomical lens (Nikon Corporation).

EPC viability assay. EPCs were divided into three groups: i) Control; ii) Netrin-1 (200 $\mathrm{ng} / \mathrm{ml})$; and iii) Netrin-1 $(200 \mathrm{ng} / \mathrm{ml})+$ CD146-siRNA. EPCs were seeded at an initial density of $1 \times 10^{5}$ cells/well in 12-well plates and incubated at $37^{\circ} \mathrm{C}$ in a $5 \% \mathrm{CO}_{2}$ incubator. Following overnight incubation to allow cells to attach to the bottom of the plates, cells were starved with $2 \%$ FBS (Lonza Group, Ltd.) containing EBM-2 for $12 \mathrm{~h}$ at $37^{\circ} \mathrm{C}$. Subsequently, cells were treated with CD146-siRNA for $24 \mathrm{~h}$, and incubated with or without Netrin-1 $(200 \mathrm{ng} / \mathrm{ml}$ in 5\% FBS containing EBM-2) for a further $24 \mathrm{~h}$ at $37^{\circ} \mathrm{C}$. At the end of the incubation, cells in each well were resuspended at room temperature in EBM-2 following trypsinization and counted using a hemocytometer.

siRNA transfection. EPCs were divided into seven groups: i) Control; ii) Netrin-1-siRNA-1; iii) Netrin-1-siRNA-2; iv) Netrin-1-siRNA-3; v) CD146-siRNA-1; vi)CD146-siRNA-2; and vii) CD146-siRNA-3. Netrin-1-siRNA (Guangzhou RiboBio Co., Ltd.) and CD146-siRNA (Thermo Fisher Scientific, Inc.) were transiently transfected into cells using RNAiMAX reagent (Thermo Fisher Scientific, Inc.). Briefly, siRNA $(60 \mathrm{nM})$ was diluted in serum-free EBM-2, then transfection 
reagent was added to the diluted siRNA, mixed by vortexing and left to form complexes for 5-10 $\mathrm{min}$ at room temperature. The complexes were subsequently added onto the cells in drops for $6 \mathrm{~h}$ at $37^{\circ} \mathrm{C}$, after which the media were replaced with EGM-2 (Lonza Group, Ltd.). Non-targeting siRNA was used as negative control (NC-siRNA of Netrin-1 from Guangzhou RiboBio Co., Ltd.; NC-siRNA of CD146 from Thermo Fisher Scientific, Inc). At $48 \mathrm{~h}$ post-transfection, the cells were used for subsequent experiments. The siRNA sequences were as follows: CD146-siRNA-1 (cat. no. MSS234801; 5'-CCAUU GUUCUGAAGCUGGUCACUUU-3'), CD146-siRNA-2 (cat. no. MSS234802; 5'-CCAAACUGGUGUG CGUCUUC UUGUU-3'), CD146-siRNA-3 (cat. no. MSS294552; 5'-CCAC AGACAGUAGUGAGCACCUUGA-3'), Netrin-1-siRNA-1 (5'-GCAGGGCACAAGTCGTATT-3'), Netrin- 1-siRNA-2 (5'-GGAAGACTGTGACTCCTAT-3') and Netrin-1-siRNA-3 (5'-GCGCGACTCCTATTACTAT-3').

TUNEL staining. EPCs were divided into five groups: i) Control; ii) OGD $6 \mathrm{~h}$; iii) OGD $6 \mathrm{~h}+$ Netrin-1 (200 ng/ml); iv) OGD $6 \mathrm{~h}+$ Netrin-1-siRNA; and v) OGD $6 \mathrm{~h}+$ Netrin-1 $(200 \mathrm{ng} / \mathrm{ml})+$ CD146-siRNA. EPCs were fixed with $4 \%$ paraformaldehyde at room temperature for $5 \mathrm{~min}$, and subsequently incubated in Triton X-100 for $25 \mathrm{~min}$ at room temperature. After washing the cells three times with PBS with $0.1 \%$ Tween-20 (PBST), TUNEL reagent (Roche Diagnostics $\mathrm{GmbH}$ ) was added to EPCs in drops and incubated for $1 \mathrm{~h}$ at $37^{\circ} \mathrm{C}$ avoiding exposure to light. Cells were subsequently washed three times with PBST, and DAPI $(10 \mu \mathrm{g} / \mathrm{ml}$, Beyotime Institute of Biotechnology) was added to each well for $5 \mathrm{~min}$ at room temperature. EPCs were captured using a confocal fluorescence microscope (Nikon A1; Nikon Corporation), and quantified and averaged by examining five random microscopic fields (magnification, x200).

Western blot analysis. EPCs were divided into the following nine groups: i) Control; ii) OGD 2 h; iii) OGD 4 h; iv) OGD 6 h; v) OGD $12 \mathrm{~h}$; vi) OGD $6 \mathrm{~h}+$ Netrin-1 (100 ng/ml); vii) OGD $6 \mathrm{~h}+$ Netrin-1 (200 ng/ml); viii) OGD $6 \mathrm{~h}+$ Netrin-1-siRNA; and ix) OGD $6 \mathrm{~h}+$ Netrin-1 (200 ng/ml) + CD146-siRNA. EPCs were harvested in lysis buffer (CST Biological Reagents Co., Ltd.) for protein extraction. The amounts of protein samples were analyzed viai the BCA assay. Equal amounts $(30 \mu \mathrm{g})$ of protein samples were treated with $5 \mathrm{X}$ loading buffer (Beyotime Institute of Biotechnology) and heated at $100^{\circ} \mathrm{C}$, then separated by $12 \%$ SDS-PAGE electrophoresis and transferred to a PVDF membrane (MilliporeSigma). The membranes were subsequently blocked with $5 \%$ non-fat milk for $1 \mathrm{~h}$ at room temperature and incubated with primary antibodies against Netrin-1 (1:1,000; cat. no. ab126729; Abcam), cleaved caspase-3 (1:1,000; cat. no. 9664; CST Biological Reagents Co., Ltd.) caspase-3 (1:1,000; cat. no. 9662; CST Biological Reagents Co., Ltd.) cleaved poly (ADP-ribose) polymerase-1 (parp-1; 1:1,000; cat. no. ab32064; Abcam), parp-1 (1:1,000; cat. no. ab191217; Abcam), Neogenin (NEO1; 1:1,000; cat. no. NBP1-89651; Novus Biologicals, Ltd.), CD146 (1:1,000; cat. no. ab75769; Abcam) or $\beta$-actin (1:2,000; cat. no. AP0060; Bioworld Technology, Inc.) at $4^{\circ} \mathrm{C}$ overnight. Following primary incubation, membranes were incubated with horseradish peroxidase-conjugated secondary antibodies anti-mouse (cat. no. BS13278; 1:5,000; Bioworld Technology, Inc.) or anti-rabbit (cat. no. BS13278; 1:5,000; Bioworld Technology, Inc.) at room temperature for $1 \mathrm{~h}$ after standard washing procedures by washing 3 times with PBS and $0.1 \%$ Tween-20. Finally, the bands were visualized using the chemiluminescence kit (Cell Signaling Technology, Inc.) and X-ray films (Kodak). The band densities were quantified using ImageJ software (version $1.48 \mathrm{u}$; National Institutes of Health).

Reverse transcription-quantitative $(R T-q) P C R$. Total RNA was extracted from EPCs without any treatment using TRIzol ${ }^{\circledR}$ (Invitrogen; Thermo Fisher Scientific, Inc.). Total RNA was reverse transcribed into cDNA using an M-MLV Reverse Transcription kit (Takara Bio, Inc.) according to the manufacturer's protocol. qPCR of known receptors of Netrin-1 was performed using a SYBR Green PCR Mix (Takara Bio, Inc.). The following thermocycling conditions were used for qPCR: Initial denaturation at $95^{\circ} \mathrm{C}$ for $1 \mathrm{~min}$; followed by 40 cycles of $95^{\circ} \mathrm{C}$ for $10 \mathrm{sec}$ and $60^{\circ} \mathrm{C}$ for $15 \mathrm{sec}$. The $2^{-\Delta \Delta \mathrm{Cq}}$ method $(23)$ was used to measure the fold-change between samples, and GAPDH was used as a normalization control. The primers were as follows: Netrin receptor UNC (UNC)5A forward, 5'-ACCTCTGAGGCTGAGGACTTC-3' and reverse, 5'-GGCT TGTGCAGAGTGAGGTAG-3'; UNC5B forward, 5'-AGTGTC AGCGGCACCTTT-3' and reverse, 5'-GGCTCAATACTGTC TGGGAAC-3'; UNC5C forward, 5'-AACTCTCTT GGGGGT CACCT-3' and reverse, 5'-TGCAG AGTGAGGATGACAGG-3'; UNC5D forward, 5'-CCTGAGTCCTGAAGTCACCTG-3' and reverse, 5'-ATGTGGACTCATCCTCCACTG-3'; Netrin receptor DCC forward, 5'-AGTCGCTTTGTCCGTTTG-3' and reverse, 5'-TCCCTGTTGTCACCCTCT-3'; NEO1 forward, 5'-AGT TAGAGGCTCTTCTGTTAT-3' and reverse, 5'-GTCCCATC TTTCTTCCAT-3'; Down syndrome cell adhesion molecule (DSCAM) forward, 5'-AACGCTAACCTGCTTCCT-3' and reverse, 5'-CTCCСТCGTCAACTTCTTT-3'; and CD146 forward, 5'-ATACCTGACTCCAGCCAAAC-3' and reverse, 5'-ACAGCCACGATGACCACA-3'; and GAPDH forward, 5'-ACTCCACTCACGGCAAATTC-3' and reverse, 5'-TCT CCATGGTGGTGAAGACA-3'.

Statistical analysis. All data are presented as the mean \pm standard error of the mean. Differences between two groups were analyzed using an unpaired Student's t-test for continuous variables, and one-way ANOVA followed by a Tukey's post hoc test were used when multiple groups were compared. Four independent experiments were performed. $\mathrm{P}<0.05$ was considered to indicate a statistically significant difference. All statistical analyses were performed using GraphPad Prism 8.0.1 (GraphPad Software, Inc.).

\section{Results}

Effects of Netrin-1 on the function of EPCs. EPCs isolated from the bone marrow of C57/BL6 mice were cultured, and the physiological concentration of Netrin-1 in EPCs was detected at $108.15 \pm 7.74 \mathrm{pg} / \mathrm{ml}$ according to an ELISA assay (data not shown). Thus, EPCs were treated with Netrin-1 $(200 \mathrm{ng} / \mathrm{ml})$ or Netrin-1-siRNA to determine the effects of Netrin-1 on the function of EPCs. Following treatment with Netrin-1, 
A
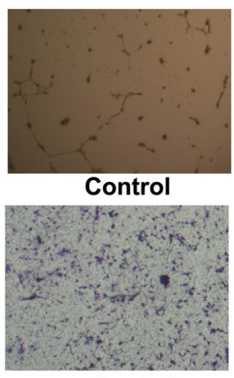

Control
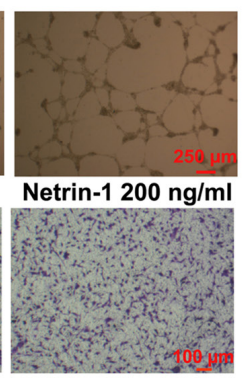

Netrin-1 200 ng/ml

B

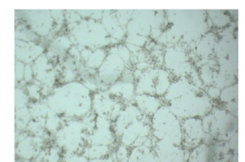

Control
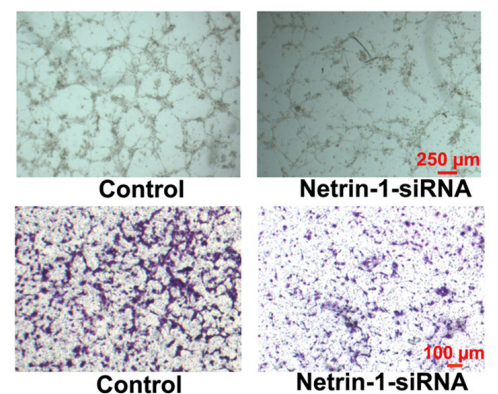

Netrin-1-siRNA
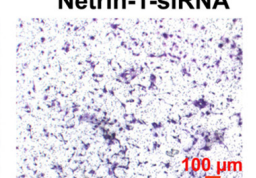

Netrin-1-siRNA
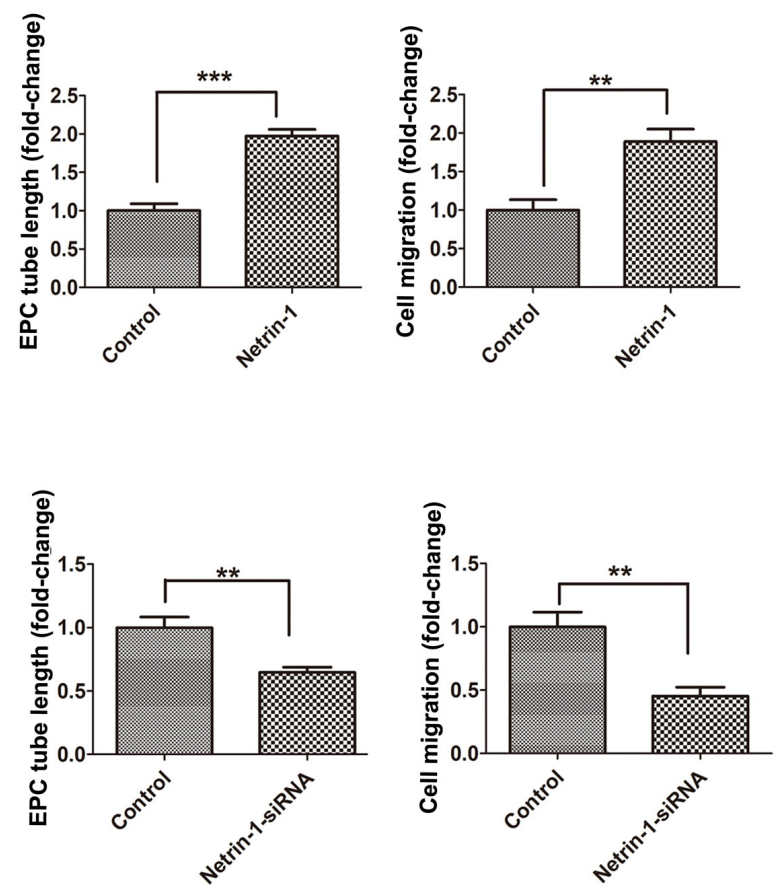

Figure 1. Exogenous Netrin-1 enhances EPC function and endogenous Netrin-1 silencing inhibits EPC function. The 7-day-cultured EPCs were treated with (A) Netrin-1 (200 ng/ml) for $24 \mathrm{~h}$, or (B) Netrin-1-siRNA for $48 \mathrm{~h}$. EPC function was examined by cell migration and tube formation assays. Values are presented as the mean \pm standard error of the mean $\left(n=4\right.$ per group). ${ }^{* *} \mathrm{P}<0.01,{ }^{* * *} \mathrm{P}<0.001$. EPC, endothelial progenitor cell; si, small interfering.

the tube formation and cell migration of EPCs was significantly increased compared with those in the control group (Fig. 1A). Moreover, the tube formation and cell migration of the Netrin-1-siRNA-treated EPC group were significantly decreased compared with those in the control group (Fig. 1B). These results suggested that endogenous Netrin-1 was essential for maintaining EPC function, which was further enhanced following treatment with exogenous Netrin-1.

Effects of Netrin-1 on the apoptosis of EPCs under hypoxic stimulation. The changes in endogenous Netrin-1 were detected under conditions of hypoxia stimulated by OGD for 2, 4, 6 and $12 \mathrm{~h}$. Results of the present study demonstrated that the protein expression levels of Netrin-1 under hypoxic stimulation increased from 2-12 h, compared with control EPCs (Fig. 2A). Results of our previous study (16) demonstrated that hypoxic stimulation for $6 \mathrm{~h}$ resulted in significant, but not excessive injury in EPCs. In the present study, Netrin-1 protein expression was significantly increased under conditions of hypoxic stimulation for $6 \mathrm{~h}$ compared with control EPCs (Fig. 2A). Thus, $6 \mathrm{~h}$ of hypoxic stimulation was used for subsequent experiments.

Subsequently, EPCs were treated with Netrin-1 or Netrin-1-siRNA, and the protein expression levels of cleaved caspase- 3 and cleaved parp-1, and the number of TUNEL-positive EPCs were detected. Following incubation with Netrin-1 (100 and $200 \mathrm{ng} / \mathrm{ml}$ ) for $24 \mathrm{~h}$ and hypoxic stimulation for $6 \mathrm{~h}$, the protein expression levels of cleaved caspase- 3 and cleaved parp-1, and the number of TUNEL-positive EPCs were significantly decreased when compared with control EPCs (Fig. 2C and E). Following transfection with
Netrin-1-siRNA-1, Netrin-1-siRNA-2 and Netrin-1-siRNA-3, transfection efficiency was determined (Fig. 2B). Due to the highest level of transfection efficiency, Netrin-1-siRNA-2 was chosen to silence Netrin-1 in subsequent experiments. Following transfection with Netrin-1-siRNA-2, the intracellular concentration of Netrin-1 was reduced to $34.66 \pm 6.28 \mathrm{pg} / \mathrm{ml}$, according to the results of an ELISA assay (data not shown) compared with control EPCs $(108.15 \pm 7.74 \mathrm{pg} / \mathrm{ml})$. Results of the present study demonstrated that the protein expression levels of cleaved caspase- 3 and cleaved parp-1, and the number of TUNEL-positive EPCs were significantly increased in the Netrin-1-siRNA group, compared with those in the OGD group (Fig. 2D and E). These results suggested that endogenous Netrin-1 induced by stress under hypoxia may perform a protective action against hypoxia environments, as the apoptosis of EPCs was exacerbated following transfection with Netrin-1-siRNA, but this was reversed following treatment with exogenous Netrin-1.

CD146 is screened out from receptors of Netrin-1. The expression levels of known receptors of Netrin-1 (Fig. 3A) were screened via RT-qPCR. Results of the present study demonstrated that UNC5B, NEO1 and CD146 were expressed at markedly higher levels in EPCs (Fig. 3B) compared with the other five ones. UNC5B mediates the inhibitory effects of Netrin-1 at high doses in other organs and tissues, such as endothelial cells and neurons (24), and the results of the present study further revealed the inhibitory action of high-dose Netrin-1 $(1,000 \mathrm{ng} / \mathrm{ml})$ in EPCs (data not shown). The present study focused on the roles of NEO1 and CD146 following treatment with Netrin-1, and western blot analysis revealed 
A

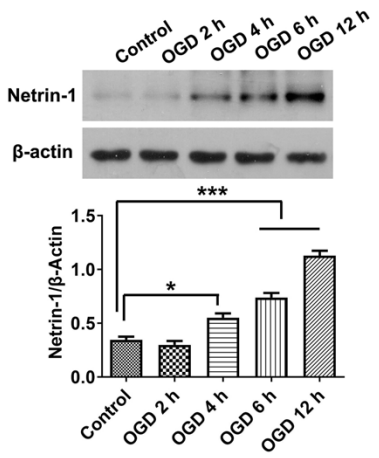

B
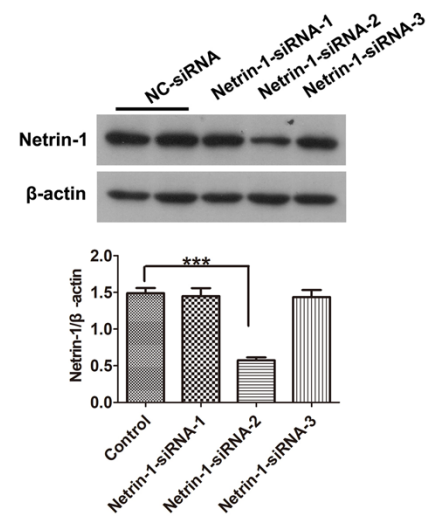

C

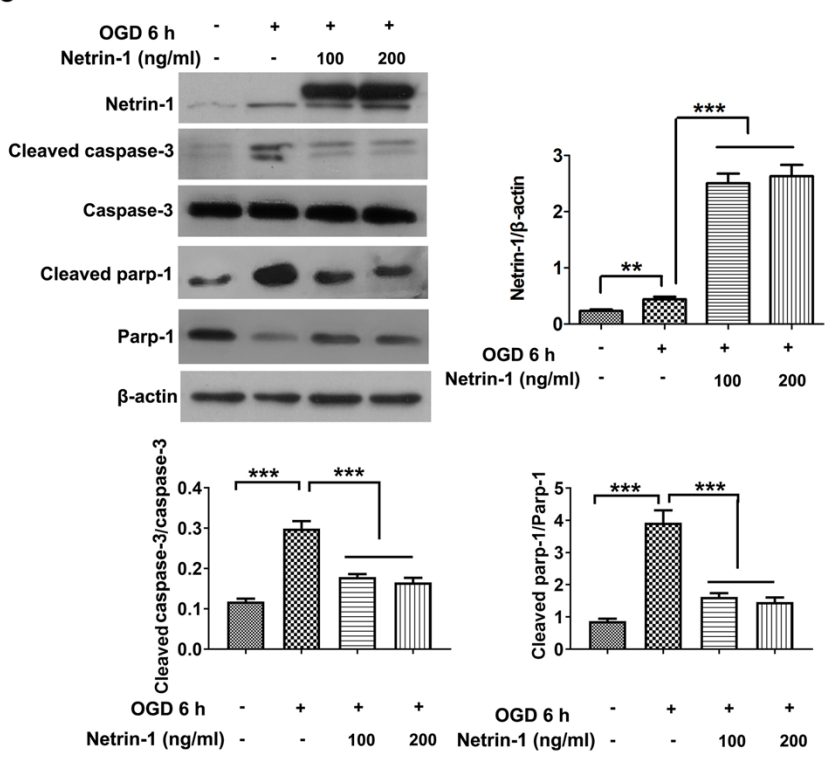

E
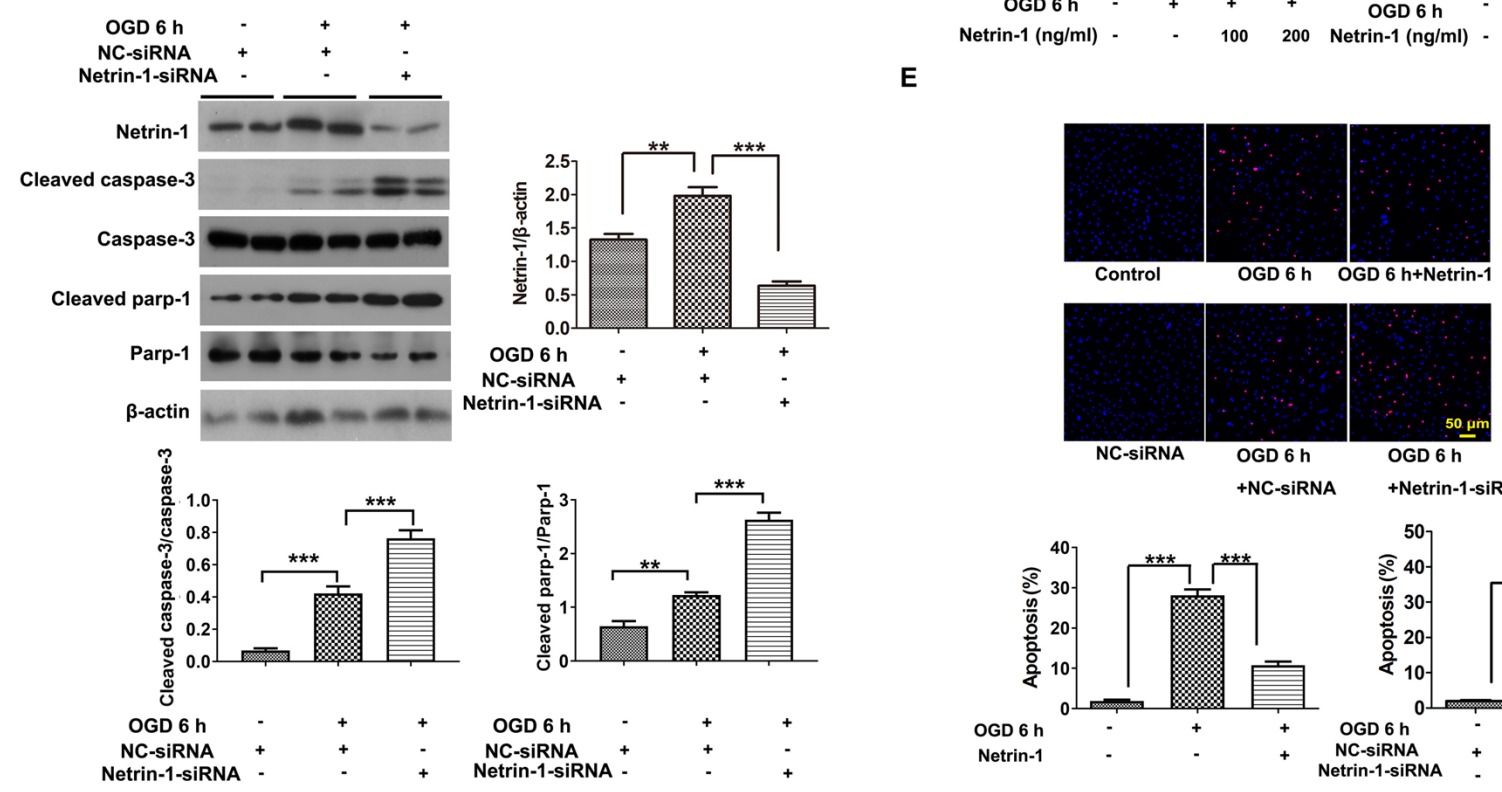

Figure 2. Exogenous Netrin-1 reduces EPC apoptosis and endogenous Netrin-1 silencing exacerbates EPC apoptosis under conditions of hypoxia. The 7-day-cultured EPCs were treated with Netrin-1 (100 or $200 \mathrm{ng} / \mathrm{ml}$ ) for $24 \mathrm{~h}$, or Netrin-1-siRNA for $48 \mathrm{~h}$, and subsequently stimulated by OGD for $6 \mathrm{~h}$ to induce hypoxia. (A-D) Western blot analysis of Netrin-1, cleaved caspase-3, caspase-3, cleaved parp-1 and parp-1. (E) Representative images and quantitative analysis of TUNEL-positive cells (red) and DAPI-stained cell nuclei (blue). Values are presented as the mean \pm standard error of the mean ( $\mathrm{n}=4$ per group). ${ }^{*} \mathrm{P}<0.05$, ${ }^{* *} \mathrm{P}<0.01,{ }^{* * *} \mathrm{P}<0.001$. EPC, endothelial progenitor cell; si, small interfering; parp-1, poly (ADP-ribose) polymerase-1; OGD, oxygen and glucose deprivation; $\mathrm{NC}$, negative control.

that the protein expression of NEO1 in EPCs was significantly reduced following treatment with Netrin-1 compared with the OGD group (Fig. 3D-F). Thus, CD146 was selected for subsequent analyses.

Anti-apoptotic role of Netrin-1 mediated by CD146 in EPCs. EPCs were transfected with CD146-siRNA-1, CD146-siRNA-2 and CD146-siRNA-3, and CD146-siRNA-1 was selected for use in subsequent experiments due to the highest level of transfection efficiency (Fig. 3C). Following transfection with CD146-siRNA-1, the intracellular concentration of CD146 was reduced to $175.80 \pm 23.70 \mathrm{ng} / \mathrm{ml}$, according to the results of an ELISA assay (data not shown) compared with control EPCs $(804.72 \pm 56.33 \mathrm{ng} / \mathrm{ml})$. Results of the present study demonstrated that transfection with CD146-siRNA exhibited no significant effects on Netrin-1-induced tube formation, EPC migration or viability (Fig. 4A-E) compared with the NC-siRNA group. Following transfection with CD146-siRNA under conditions of hypoxia, CD146 expression in the CD146-siRNA group significantly decreased compared with the control group, and CD146 expression in the Netrin-1 plus CD146-siRNA group significantly decreased compared with the Netrin-1 group (Fig. 5A). The protective effect of Netrin-1 $(200 \mathrm{ng} / \mathrm{ml})$ on EPCs was significantly impaired after delivery of CD146-siRNA, as indicated by the increased protein expression levels of cleaved caspase-3 and cleaved parp-1, and an increased number of TUNEL-positive EPCs (Fig. 5A and B). Collectively, the results of the present study implied that CD146 may play a role in mediating Netrin-1 in the apoptosis of EPCs, rather than overall EPC function. 
A
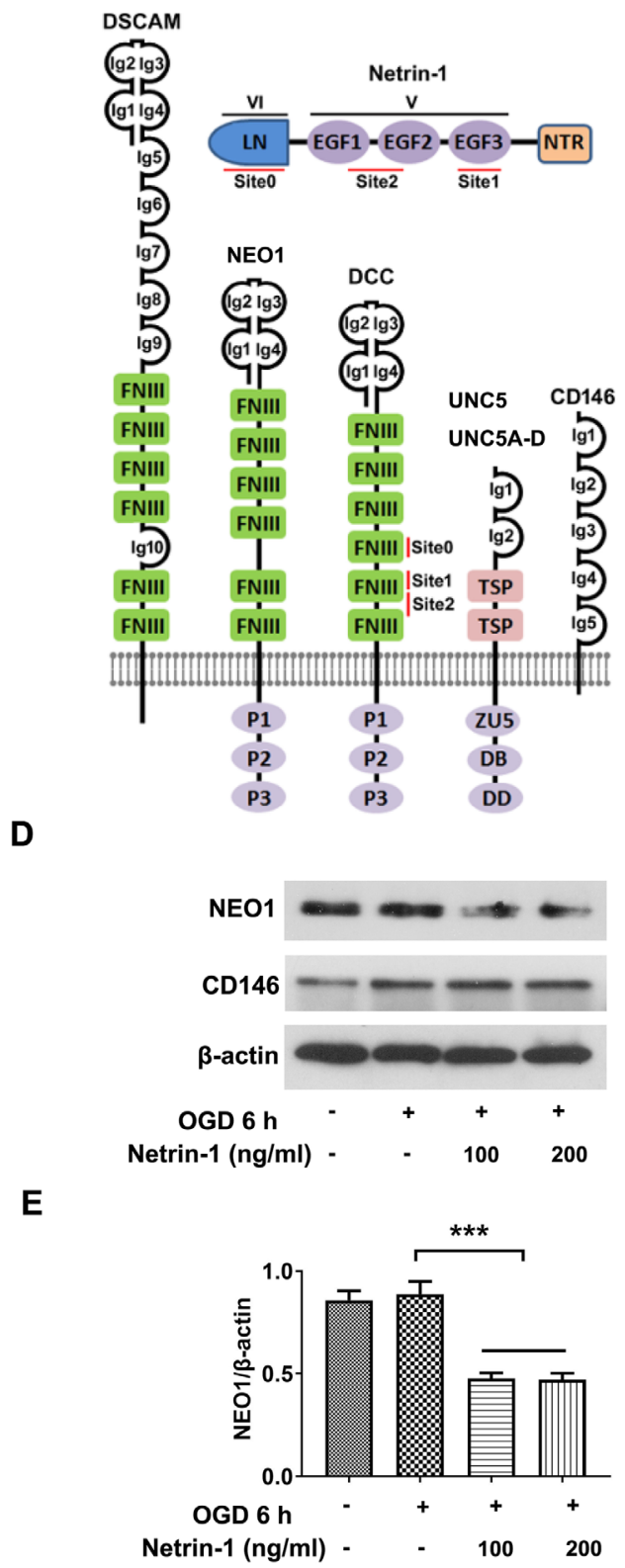

B
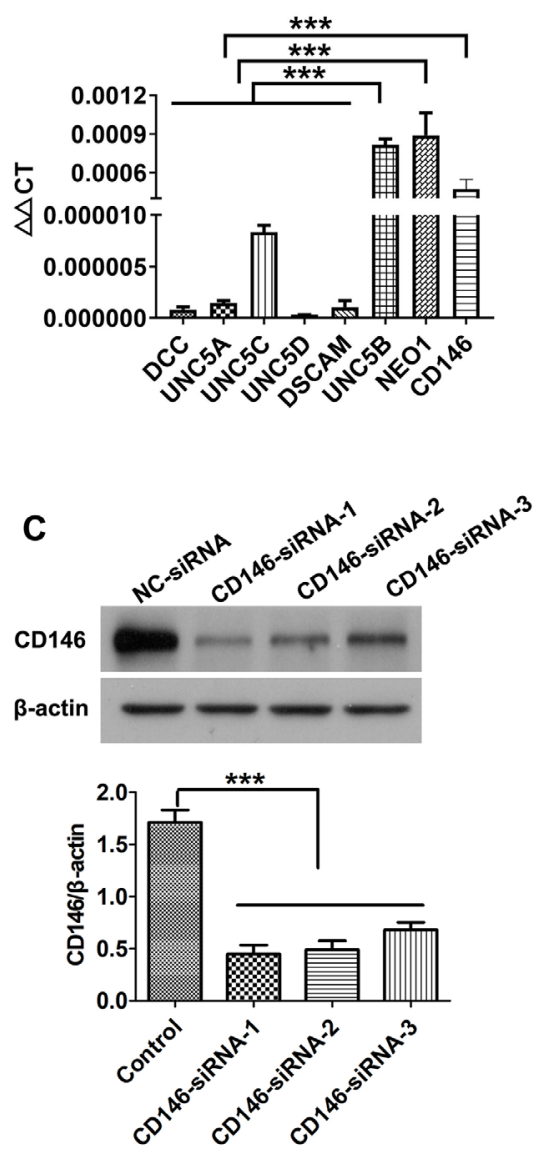

$\mathbf{F}$

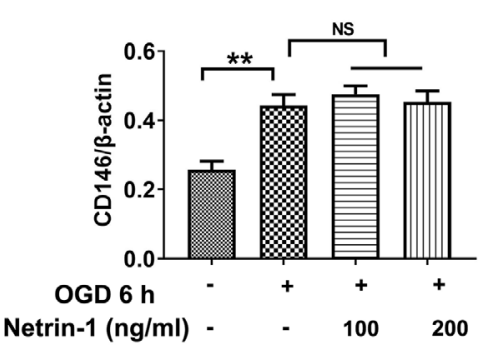

Figure 3. Screening Netrin-1 receptors. (A) Structure of Netrin-1 and the associated receptors. (B) Reverse transcription-quantitative PCR analysis of the mRNA expression levels of Netrin-1 receptors. (C-F) Western blot analysis of NEO1 and CD146. Values are presented as the mean \pm standard error of the mean ( $\mathrm{n}=4$ per group). ${ }^{* *} \mathrm{P}<0.01 ;{ }^{* * * *} \mathrm{P}<0.001$. LN, laminin-like domain (also known as domain VI); EGF1-3, epidermal growth factor repeats (EGF1, EGF2 and EGF3 also known as domain V); NTR, C-terminal Netrin-like domain; Ig, immunoglobulin; FNIII, fibronectin type III domain; TSP, thrombospondin type 1 (TSP-1) domain; ZU5, zona occludens 5 (ZU5) domain; DB, DCC-binding domain; DD, death domain; NEO1, neogenin; DSCAM, down syndrome cell adhesion molecule; DCC, Netrin receptor DCC; UNC, Netrin receptor UNC; OGD, oxygen and glucose deprivation.

\section{Discussion}

Results of the present study demonstrated that Netrin-1 regulated EPC function and hypoxia-induced cell injury. Silencing of endogenous Netrin-1 impaired the proangiogenic function and survival of EPCs. Conversely, treatment with exogenous Netrin-1 enhanced the angiogenic activity of EPCs, and reduced the levels of apoptosis under hypoxic conditions. The CD146 receptor mediated the anti-apoptotic role of exogenous Netrin-1, rather than the overall proangiogenic function. Collectively, these findings suggested a novel biological role of Netrin-1 in EPC therapy associated with ischemic vascular disease.
The discovery of EPCs resulted in a paradigm shift in vascular biology, highlighting that adult vessels are repaired not only by the local proliferation, migration and remodeling of endothelial cells, but also by the incorporation of EPCs in developing new blood vessels (25-27). Numerous studies have demonstrated that EPCs are recruited to the site of vascular damage, where they migrate and adhere to the vessel wall, promoting the re-endothelialization of damaged vessels and inducing vasculogenesis in ischemic areas (28-30). In the present study, Netrin-1 sequentially participated in EPC migration and vessel formation, as indicated not only by treatment with exogenous Netrin-1, but also by the interference of endogenous Netrin-1 expression. This result implied the positive role 
A

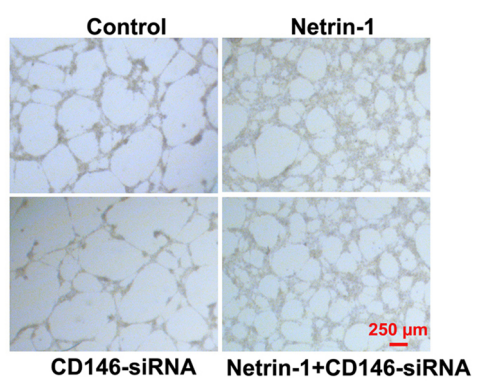

B

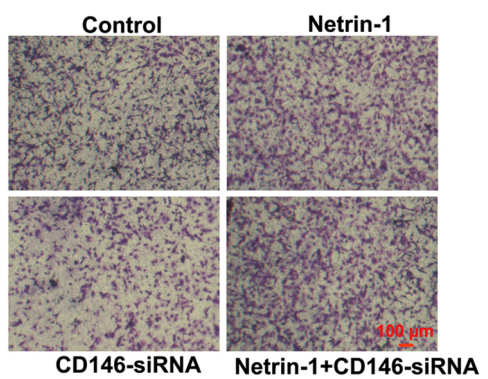

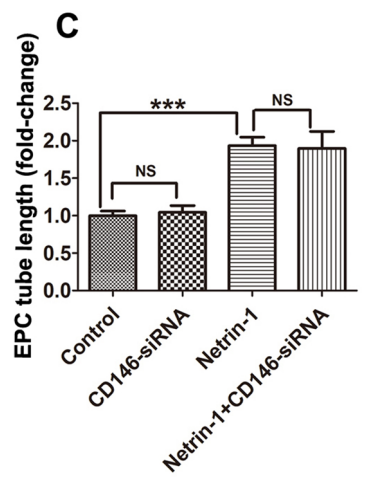

D

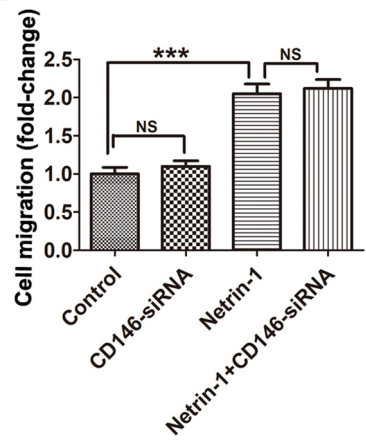

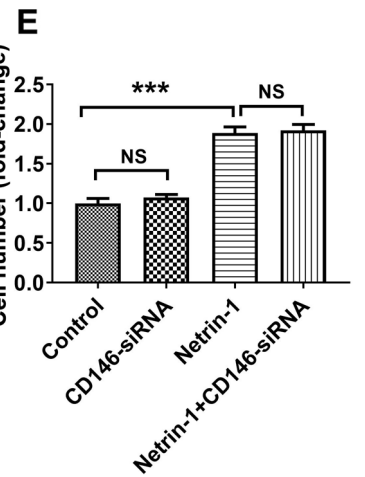

Figure 4. Impact of CD146 on the role of Netrin-1 in EPC function. The 7-day-cultured EPCs were treated with CD146-siRNA for $24 \mathrm{~h}$, and subsequently treated with exogenous Netrin-1 $(200 \mathrm{ng} / \mathrm{ml})$ for a further $24 \mathrm{~h}$. EPC function was examined by (A) the image of tube formation, (B) the graph of tube formation, (C) the picture of cell migration, (D) the graph of cell migration and (E) the graph of cell viability. Values are presented as the mean \pm standard error of the mean ( $\mathrm{n}=4$ per group). ${ }^{* * *} \mathrm{P}<0.001$. EPC, endothelial progenitor cell; si, small interfering; NS, not significant.

A
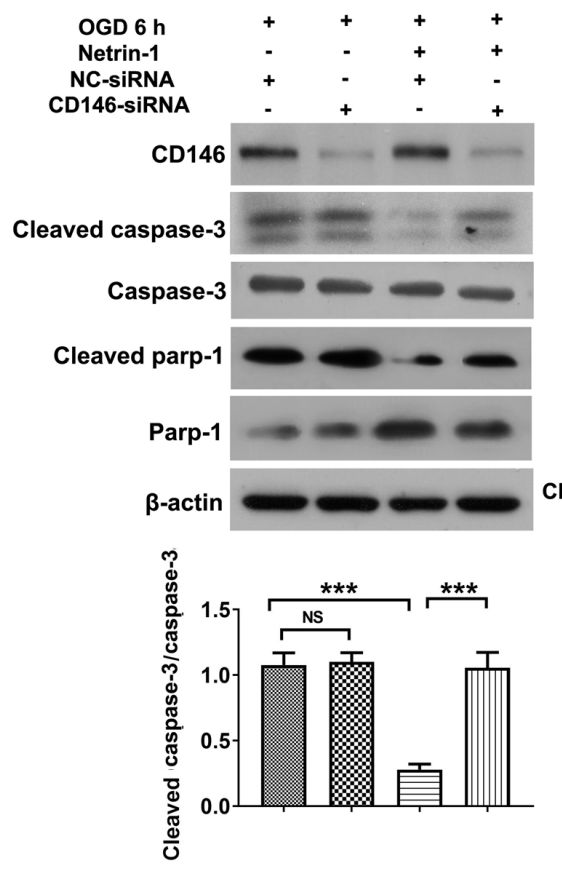
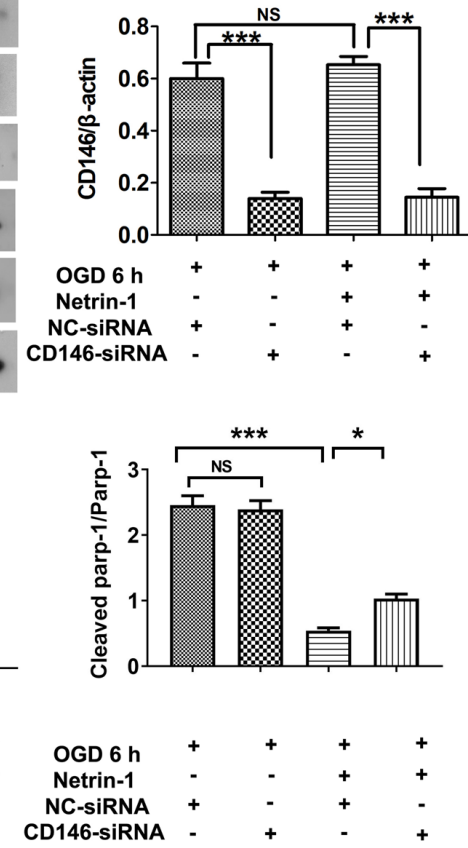

B
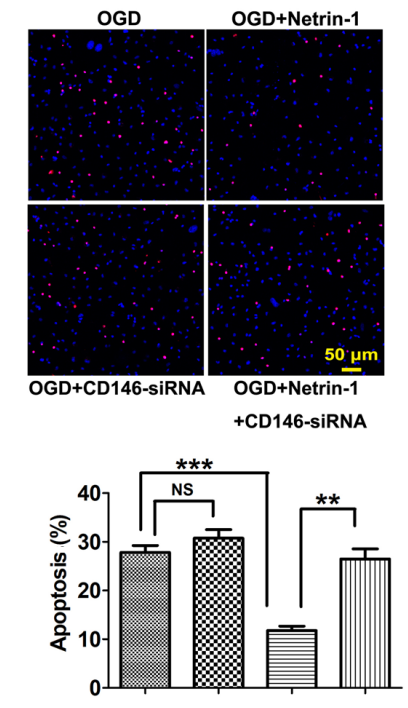

$\begin{array}{ccccc}\text { OGD 6 h } & + & + & + & + \\ \text { Netrin-1 } & - & - & + & + \\ \text { NC-siRNA } & + & - & + & - \\ \text { CD146-siRNA } & + & + & - & +\end{array}$

Figure 5. CD146 mediates the anti-apoptotic role of Netrin-1 in EPCs under hypoxic conditions. The 7-day-cultured EPCs were treated with CD146-siRNA for $24 \mathrm{~h}$, and subsequently treated with exogenous Netrin-1 (200 ng/ml) for a further $24 \mathrm{~h}$. (A) Western blot analysis of CD146, cleaved caspase-3, caspase-3, cleaved parp-1 and parp-1. (B) Representative images and quantitative analysis of TUNEL-positive cells (red) and DAPI-stained cell nuclei (blue). Values are presented as the mean \pm standard error of the mean ( $\mathrm{n}=4$ per group). ${ }^{*} \mathrm{P}<0.05,{ }^{* *} \mathrm{P}<0.01,{ }^{* * * *} \mathrm{P}<0.001$. EPC, endothelial progenitor cell; si, small interfering; parp-1, poly (ADP-ribose) polymerase-1; OGD, oxygen and glucose deprivation; NC, negative control; NS, not significant. 
of Netrin-1 in the angiogenic function of EPCs. Notably, a high dose of Netrin-1 $(1,000 \mathrm{ng} / \mathrm{ml})$ led to a decrease in the levels of EPC migration and tube formation, which may have resulted from the initiation of the UNC5B receptor, similar to the role of high-dose Netrin-1 in endothelial cells (31).

Under ischemic conditions, the injury of EPCs should be emphasized rather than the function of EPCs, as the latter is closely associated with EPC viability. Results of previous studies have demonstrated that most cells $(>80 \%)$ die at $<3$ days after delivery $(32,33)$, thereby impacting the associated therapeutic effect. Under ischemia, organs develop protective mechanisms to resist a harmful environment (34). However, such protective mechanisms are insufficient, so an artificial design is required to reinforce this effect. Results of the present study revealed that Netrin-1 expression was significantly increased under hypoxic conditions, and Netrin-1 silencing markedly exacerbated EPC apoptosis compared with control EPCs, indicating that an increase in endogenous Netrin-1 protected against hypoxia-induced EPC damage. Thus, treatment with exogenous Netrin-1 suppressed EPC apoptosis, highlighting the protective effect of endogenous Netrin-1.

Receptors of Netrin-1, including DCC, UNC5, NEO1, DSCAM and CD146, belong to the immunoglobulin superfamily. These receptors are stimulated by Netrin- 1 and play key roles in a number of different diseases, such as cancer, heart failure, ischemic stroke, spinal cord injury, diabetic retinopathy and lung fibrosis (12). In EPCs, the receptor manipulated by Netrin-1 remains to be elucidated. Thus, RT-qPCR and western blot analyses were performed to screen for CD146 in EPCs in the present study. CD146, a melanoma cell adhesion molecule, is highly expressed in tumors and a number of cell types, such as endothelial cells, pericytes, smooth muscle cells, fibroblasts and mesenchymal stem cells (35). Results of previous studies have demonstrated that CD146 is not only an adhesion molecule, but also a cellular surface receptor stimulated by miscellaneous ligands, including extracellular matrices and growth factors $(36,37)$. By binding to its corresponding ligands, CD146 closely participates in a number of cell processes, such as proliferation, migration (38), hypertrophy (39), angiogenesis (40) and apoptosis (40,41). CD146 is mostly involved in the development and injury of organs, and the progression of various cancer types to metastases, such as oral cancer, ovarian carcinoma, hepatocellular carcinoma and acute lymphocytic leukemia (42).

Netrin-1 is a ligand of CD146 in endothelial cells, promoting angiogenesis and vascular development $(22,43,44)$. However, in the present study, CD146 participated in the anti-apoptotic role of Netrin-1 in hypoxia-induced EPCs, but did not mediate the angiogenic effect of Netrin-1 in EPCs.

Alternative receptors involved in the proangiogenic function of Netrin-1 in EPCs remain to be fully elucidated. Numerous studies have reported that DCC, UNC5B and NEO1 are associated with vessel formation (45-47). Previous studies reported that UNC5B is highly involved in anti-angiogenesis (24), and DCC and NEO1 are associated with angiogenesis $(14,21,48)$. Although the expression levels of DCC and NEO1 were low compared with CD146 expression in the present study, the specific role of DCC and NEO1 remain to be elucidated in association with Netrin-1 in EPC function. Moreover, alternative unknown receptors may be involved in the role of Netrin-1 in EPCs, and should be further investigated.

\section{Acknowledgements}

Not applicable.

\section{Funding}

The present study was supported by the National Natural Science Foundation of China (grant no. 81302767), the Science and Technology Planning Project of Guangdong Province (grant no. 2017A020215194), the Natural Science Foundation of Guangdong Province (grant no. 2021A1515011372), the High-level University Construction Fund of Guangdong Province (grant nos. 06-410-2107204 and 06-410-2107271) and the Medical Scientific Research Foundation of Guangdong Province (grant no. A2021332).

\section{Availability of data and materials}

The datasets used and/or analyzed during the current study are available from the corresponding author on reasonable request.

\section{Authors' contributions}

RCJ and XYZ contributed to design, collection and/or assembly of data, and data analysis and interpretation. SLY, HJS, JHX, YJZ, HQD and YJW contributed to collection and/or assembly of data. YQ contributed to the provision of study material, analysis and interpretation of data. QX and XLZ contributed to conception and design, financial support, administrative support, provision of study material, data analysis and interpretation and manuscript writing. QX and XLZ confirmed the authenticity of all the raw data. All authors have read and approved the final manuscript.

\section{Ethics approval and consent to participate}

The present study was approved by the Ethical Committees of Guangzhou Medical University (approval no. GY2018-092).

\section{Patient consent for publication}

Not applicable.

\section{Competing interests}

The authors declare that they have no competing interests.

\section{References}

1. Perrotta F, Perna A, Komici K, Nigro E, Mollica M, D'Agnano V, De Luca A and Guerra G: The State of Art of Regenerative Therapy in Cardiovascular Ischemic Disease: Biology, Signaling Pathways, and Epigenetics of Endothelial Progenitor Cells. Cells 9: 1886, 2020.

2. Bayraktutan U: Endothelial progenitor cells: Potential novel therapeutics for ischaemic stroke. Pharmacol Res 144: 181-191, 2019.

3. Pearson JD: Endothelial progenitor cells - hype or hope? J Thromb Haemost 7: 255-262, 2009. 
4. Li J, Ma Y, Miao XH, Guo JD and Li DW: Neovascularization and tissue regeneration by endothelial progenitor cells in ischemic stroke. Neurol Sci 42: 3585-3593, 2021.

5. Krishnamurthy P, Thal M, Verma S, Hoxha E, Lambers E, Ramirez V, Qin G, Losordo D and Kishore R: Interleukin-10 deficiency impairs bone marrow-derived endothelial progenitor cell survival and function in ischemic myocardium. Circ Res 109: 1280-1289, 2011.

6. Lee J, Shin D and Roh JL: Use of a pre-vascularised oral mucosal cell sheet for promoting cutaneous burn wound healing. Theranostics 8: 5703-5712, 2018.

7. Yue Y, Garikipati VNS, Verma SK, Goukassian DA and Kishore R: Interleukin-10 Deficiency Impairs Reparative Properties of Bone Marrow-Derived Endothelial Progenitor Cell Exosomes. Tissue Eng Part A 23: 1241-1250, 2017.

8. Chong MS, Ng WK and Chan JK: Concise Review: Endothelial Progenitor Cells in Regenerative Medicine: Applications and Challenges. Stem Cells Transl Med 5: 530-538, 2016.

9. Hung H-S, Shyu W-C, Tsai C-H, Hsu S-H and Lin S-Z: Transplantation of endothelial progenitor cells as therapeutics for cardiovascular diseases. Cell Transplant 18: 1003-1012, 2009.

10. Seeger FH, Zeiher AM and Dimmeler S: Cell-enhancement strategies for the treatment of ischemic heart disease. Nat Clin Pract Cardiovasc Med 4S: S110-S113, 2007.

11. Dun XP and Parkinson DB: Role of Netrin-1 Signaling in Nerve Regeneration. Int J Mol Sci 18: 491, 2017.

12. Boyer NP and Gupton SL: Revisiting Netrin-1: One Who Guides (Axons). Front Cell Neurosci 12: 221, 2018.

13. Wilson BD, Ii M, Park KW, Suli A, Sorensen LK Larrieu-Lahargue F, Urness LD, Suh W, Asai J, Kock GA, et al: Netrins promote developmental and therapeutic angiogenesis. Science 313: 640-644, 2006

14. Liu NM, Siu KL, Youn JY and Cai H: Attenuation of neointimal formation with netrin-1 and netrin-1 preconditioned endothelial progenitor cells. J Mol Med (Berl) 95: 335-348, 2017.

15. National Research Council (US) Committee for the Update of the Guide for the Care and Use of Laboratory Animals: Guide for the Care and Use of Laboratory Animals. 8th edition. National Academies Press (US), Washington, DC, 2011. https://www.ncbi nlm.nih.gov/books/NBK54050/doi: 10.17226/12910

16. Jiang RC, Zhang XL, Zhang QA, Zheng XY, Shi HJ, Qin Y, Zhang GP, Xiao Q and Luo JD: Impaired Vps34 complex activity-mediated autophagy inhibition contributes to endothelial progenitor cells damage in the ischemic conditions. Biochem Biophys Res Commun 524: 629-635, 2020

17. Xiao Q, Zhao XY, Jiang RC, Chen XH, Zhu X, Chen KF, Chen SY, Zhang XL, Qin Y, Liu YH, et al: Increased expression of Sonic hedgehog restores diabetic endothelial progenitor cells and improves cardiac repair after acute myocardial infarction in diabetic mice. Int J Mol Med 44: 1091-1105, 2019.

18. Ii M: Bone marrow-derived endothelial progenitor cells: Isolation and characterization for myocardial repair. Methods Mol Biol 660: 9-27, 2010.

19. Xie H, Zou L, Zhu J and Yang Y: Effects of netrin-1 and netrin-1 knockdown on human umbilical vein endothelial cells and angiogenesis of rat placenta. Placenta 32: 546-553, 2011.

20. Park KW, Crouse D, Lee M, Karnik SK, Sorensen LK, Murphy KJ, Kuo CJ and Li DY: The axonal attractant Netrin-1 is an angiogenic factor. Proc Natl Acad Sci USA 101: 16210-16215, 2004.

21. Nguyen A and Cai $\mathrm{H}$ : Netrin-1 induces angiogenesis via a DCC-dependent ERK1/2-eNOS feed-forward mechanism. Proc Natl Acad Sci USA 103: 6530-6535, 2006.

22. Tu T, Zhang C, Yan H, Luo Y, Kong R, Wen P, Ye Z, Chen J, Feng J, Liu F, et al: CD146 acts as a novel receptor for netrin-1 in promoting angiogenesis and vascular development. Cell Res 25: 275-287,2015.

23. Livak KJ and Schmittgen TD: Analysis of relative gene expression data using real-time quantitative PCR and the $2(-\Delta \Delta \mathrm{C}(\mathrm{T}))$ Method. Methods 25: 402-408, 2001.

24. Freitas C, Larrivée B and Eichmann A: Netrins and UNC5 receptors in angiogenesis. Angiogenesis 11: 23-29, 2008.

25. Galasso G, De Rosa R, Ciccarelli M, Sorriento D, Del Giudice C, Strisciuglio T, De Biase C, Luciano R, Piccolo R, Pierri A, et al: $\beta 2$-Adrenergic receptor stimulation improves endothelial progenitor cell-mediated ischemic neoangiogenesis. Circ Res 112: 1026-1034, 2013.

26. Keighron C, Lyons CJ, Creane M, O'Brien T and Liew A: Recent Advances in Endothelial Progenitor Cells Toward Their Use in Clinical Translation. Front Med (Lausanne) 5: 354, 2018.
27. Chopra H, Hung MK, Kwong DL, Zhang CF and Pow EHN: Insights into Endothelial Progenitor Cells: Origin, Classification, Potentials, and Prospects. Stem Cells Int 2018: 9847015, 2018.

28. Kaushik K and Das A: Endothelial progenitor cell therapy for chronic wound tissue regeneration. Cytotherapy 21: 1137-1150, 2019.

29. Bongo JB and Peng DQ: The neuroimmune guidance cue netrin-1: A new therapeutic target in cardiovascular disease. J Cardiol 63: 95-98, 2014

30. Ding Q, Liao SJ and Yu J: Axon guidance factor netrin-1 and its receptors regulate angiogenesis after cerebral ischemia. Neurosci Bull 30: 683-691, 2014.

31. Larrivée B, Freitas C, Trombe M, Lv X, Delafarge B, Yuan L, Bouvrée K, Bréant C, Del Toro R, Bréchot N, et al: Activation of the UNC5B receptor by Netrin-1 inhibits sprouting angiogenesis. Genes Dev 21: 2433-2447, 2007.

32. Pedroso DC, Tellechea A, Moura L, Fidalgo-Carvalho I, Duarte J, Carvalho E and Ferreira L: Improved survival, vascular differentiation and wound healing potential of stem cells co-cultured with endothelial cells. PLoS One 6: e16114, 2011.

33. Bompais H, Chagraoui J, Canron X, Crisan M, Liu XH, Anjo A, Tolla-Le Port C, Leboeuf M, Charbord P, Bikfalvi A, et al: Human endothelial cells derived from circulating progenitors display specific functional properties compared with mature vessel wall endothelial cells. Blood 103: 2577-2584, 2004.

34. Li S, Hafeez A, Noorulla F, Geng X, Shao G, Ren C, Lu G, Zhao H, Ding Y and Ji X: Preconditioning in neuroprotection: From hypoxia to ischemia. Prog Neurobiol 157: 79-91, 2017.

35. Wang Z, Xu Q, Zhang N, Du X, Xu G and Yan X: CD146, from a melanoma cell adhesion molecule to a signaling receptor. Signal Transduct Target Ther 5: 148, 2020.

36. Wang Z and Yan X: CD146, a multi-functional molecule beyond adhesion. Cancer Lett 330: 150-162, 2013.

37. Piao Y, Guo H, Qu Z, Zheng B and Gao Y: CD146 promotes migration and proliferation in pulmonary large cell neuroendocrine carcinoma cell lines. Oncol Lett 17: 2075-2080, 2019.

38. Obara M, Sato S, Takahashi K, Kondo Y, Hirose M, Nata K and Taira E: Expression of cell adhesion molecule, Gicerin/CD146 during the formation of heart and in the cardiac hypertrophy. Mol Cell Biochem 476: 2021-2028, 2021.

39. Joshkon A, Heim X, Dubrou C, Bachelier R, Traboulsi W, Stalin J, Fayyad-Kazan H, Badran B, Foucault-Bertaud A, Leroyer AS, et al: Role of CD146 (MCAM) in Physiological and Pathological Angiogenesis-Contribution of New Antibodies for Therapy. Biomedicines 8: 633, 2020.

40. Nodomi S, Umeda K, Saida S, Kinehara T, Hamabata T, Daifu T, Kato I, Hiramatsu H, Watanabe KI, Kuwahara Y, et al: CD146 is a novel marker for highly tumorigenic cells and a potential therapeutic target in malignant rhabdoid tumor. Oncogene 35: 5317-5327, 2016 .

41. Jouve N, Despoix N, Espeli M, Gauthier L, Cypowyj S, Fallague K, Schiff C, Dignat-George F, Vély F and Leroyer AS: The involvement of CD146 and its novel ligand Galectin-1 in apoptotic regulation of endothelial cells. J Biol Chem 288: 2571-2579, 2013

42. Stalin J, Nollet M, Dignat-George F, Bardin N and Blot-Chabaud M: Therapeutic and Diagnostic Antibodies to CD146: Thirty Years of Research on Its Potential for Detection and Treatment of Tumors. Antibodies (Basel) 6: 17, 2017.

43. Guo X, Ding S, Li T, Wang J, Yu Q, Zhu L, Xu X, Zou G, Peng Y and Zhang X: Macrophage-derived netrin-1 is critical for neuroangiogenesis in endometriosis. Int J Biol Macromol 148: 226-237, 2020

44. St Croix B: CD146: The unveiling of a pro-angiogenic netrin receptor. Cell Res 25: 533-534, 2015.

45. Claro V and Ferro A: Netrin-1: Focus on its role in cardiovascular physiology and atherosclerosis. JRSM Cardiovase Dis 9: $2048004020959574,2020$.

46. Castets $M$ and Mehlen P: Netrin-1 role in angiogenesis: To be or not to be a pro-angiogenic factor? Cell Cycle 9: 1466-1471, 2010

47. Wilson NH and Key B: Neogenin: One receptor, many functions. Int J Biochem Cell Biol 39: 874-878, 2007.

48. Yao LL, Hu JX, Li Q, Lee D, Ren X, Zhang JS, Sun D, Zhang HS, Wang YG, Mei L, et al: Astrocytic neogenin/netrin-1 pathway promotes blood vessel homeostasis and function in mouse cortex. J Clin Invest 130: 6490-6509, 2020.

This work is licensed under a Creative Commons Attribution-NonCommercial-NoDerivatives 4.0 International (CC BY-NC-ND 4.0) License. 